\title{
Filament Wound Filter Housing - Key for Rational Purification Process of Highly Corrosive Solutions
}

\author{
Jovan Radulović ${ }^{1)}$ \\ Radovan Karkalić ${ }^{2)}$
}

\begin{abstract}
Practical and realistic approach for a successful use of filament wound filter housing based on bisphenol A polyester resin for purification of highly corrosive contaminated solutions is presented in this paper.

Filament winding technology and basic terms about polyester and polymeric composite materials are described. Data about modes of producing neat (no reinforced) bisphenol A polyester resin specimens and composite material specimen, based on mentioned resin and glass fiber, are presented. Neat resin specimens were exposed to the single influence of aqueous solution of calcium hypochlorite, of sodium hydroxide, of sulphuric acid, of citric acid and liquid detergent for a period of 360 hours each, separately, and to the cumulative influence of all mentioned aqueous solutions for in overall period of 1440 hours. Tested properties of these specimens (mass change, hardness and impact resistance) showed that there is no negative influence on neat bisphenol A polyester resin quality. Filament wound composite reinforced glass fiber/bisphenol A polyester resin-based rings and cylinders were exposed to the influence of calcium hypochlorite aqueous solution for 1128 hours. Results of testing mass change, tensile breaking force and tensile strength of composite reinforced rings and hydraulic burst pressure of composite reinforced cylinders indicated that these specimens have high resistance to mentioned purification agent. It is concluded that the filter housing for purification of highly corrosive contaminated solutions can be produced by filament winding technology using bisphenol A polyester resin and glass fiber.
\end{abstract}

Key words: filament winding technology, purification of corrosive solutions, filter housing, polyester bisphenol A resin, mechanical characteristics, physical properties.

\section{Introduction}

$\mathrm{P}$ URIFICATION of solutions, which has corrosive action, is very important activity from several points of view.

Calcium hypochlorite, which is often used as an agent for purification of particular solutions, is an oxidizing agent and can have corrosive action to some metals, being responsible of corrosion problems in metallic pipes [1].

Corrosion processes consist of a series of electrochemical reactions occurring at the metal surface in contact with water and its constituents. Corrosivity of particular water solutions depends on its chemical properties and physical characteristics, as well as the nature of the pipe, i.e. housing material $[2,3]$.

In order to realize a purification of particular water solutions in satisfactory way, several problems had to be solved.

One of the most important problems was manufacturing of filter housing for purification of this kind of solutions and at one time it was solved by using very expensive alloyed and highly protected steel. This steel housing had a limited using period because of highly aggressive corrosive action of solution that was purified.

Polymeric based composite materials are characterized by a set of unique properties so they replaced classical construction materials and very often are the only choice for numerous purposes. These newer materials are produced by the various technologies.
Unsaturated polyester resins pieces are much favoured over their metallic counterparts. With the current fuel and processing costs, the increasing prices of steel and aluminium are pushing more fabricators to use unsaturated polyester resin composites instead of mentioned metals.

Another major advantage is the increased productivity potential. While metals involve the use of specific smelters, expensive tooling and processing requirements, unsaturated polyester resins are far cheaper and afford the use of low cost tooling. An unsaturated polyester resin can be moulded at ambient temperature whereas metals need to be heated to well over $2000^{\circ} \mathrm{C}$ before they are melted and poured into mould cavities.

Although the perception is that metals are generally structurally superior, there has been much advancement in the development of technologies for producing higher strength composites made from unsaturated polyesters resins.

Maybe the most potential advantage of unsaturated polyesters composite over their metallic counterparts is global focus on greener processes and technologies. Production of metals continues to deplete our natural resources and consumes most of our fossil fuels. Unsaturated polyesters, although previously synthesized from fossil fuels, can now be manufactured from biological resources instead (starches, plant oils and other naturally derived materials) [4].

The corrosion resistance of fiber reinforced polymers is a function of both the production technology and the specific

\footnotetext{
1) Military Technical Institute (VTI), Ratka Resanovića 1, 11132 Belgrade, SERBIA

2) Military Academy, University of Defense, 11000 Belgrade, SERBIA

Correspondence to: Jovan Radulović, e-mail: jovan.r.radulovic@gmail.com
} 
resin used in the composite material. Today, various resin systems are available which can provide long-resistance to almost every chemical.

Composite pipes are light weight (1/4 the weight of mostly metallic pipes), smooth internal surface, (lower friction means lower pumped costs or better flow in gravity systems), fabricated fittings are more economical than almost all other pipe materials and speed of installation is very rational [5].

Fiber-reinforced polymeric composite pipes are used in many diverse applications and are subjected to various rough service conditions during their service life. The investigation of mechanical and physical properties and chemical resistance of these pipes is essential to estimate their long-term performance in specific applications.

Using of very expensive housing, made of especially protected steel materials, in filter for purification of highly corrosive solutions were possible in very short period of time.

This investigation represents an attempt to establish important elements, which will be a base for production of filter housing by filament winding technology of glass fiber impregnated with bisphenol A polyester resin. It was planned that investigation provided specific, original data about resistance of this plastic composite housing toward substances used in purification process of highly corrosive solutions, and real indicators of mechanical and physical characteristics of mentioned housing.

In available literature, except general statements of advantages of plastic composite pipes over metallic pipes in systems for purification and transport various liquids, there are only few specific data about chemical resistance of plastic parts toward substances and mechanical and physical loading, which occurs in these processes.

Starting considerations have taken into account low price of domestic glass fiber, relatively high corrosion and hydrolytical resistance of domestic non-expensive bisphenol A polyester resin (based on its structure), simple chosen technology of production of plastic composite housing and estimation that filament wound housing, which is significantly cheaper than very expensive steel housing, can be used for purification of highly corrosive solutions for longer period of time.

It is stated that multilayer pipe, consisting of three parts (first, external is glass fiber-reinforced epoxy composite, second, middle is high-strength stainless steel and third, internal is glass fiber-reinforced epoxy composite, again), can withstand extremely high pressure in environments exposed to corrosion. In addition to its good mechanical properties, this product is, also, claimed to be cheaper to manufacture than stainless steel pipes, with a service life of at least 30 years compared with an estimated six months to three years for stainless steel pipes in similar corrosion conditions [6].

Al-Hadhrami et al. presented the results of an investigation of preconditioned and fresh glass fiber-reinforced plastic pipe specimens. Chemical resistance (toward $\mathrm{HCl}, \mathrm{H}_{2} \mathrm{SO}_{4}$, mixture of $\mathrm{NaOH}$ and $\mathrm{KMnO}_{4}$, fresh and oily water at higher temperature and pressure for long period of time), mechanical properties (axial and hoop tensile strength) and water absorption of pipes are tested. The experimental results did not exhibit major change in the properties of evaluated pipes after exposing to clean and oily water at high temperature and pressure. There was minimal loss in the axial and hoop strength of the preconditioned pipes. The absorption did not increase significantly due to mentioned conditions. The results indicate that glass fiber-reinforced plastic pipes are suitable for application in the oil and gas industry [7].

Hale J.M. and others characterized the strength reduction of two composite materials in the form of filament wound pipes as a function of temperature and testing environment. The used materials were composites based on glass fiber as reinforcement and two epoxy resin systems as matrices. The testing environments were sea water and sea water with dissolved $\mathrm{CO}_{2}$ and $\mathrm{H}_{2} \mathrm{~S}$ gases. The temperature range tested was ambient to $150^{\circ} \mathrm{C}$. The tests were performed on filament wound pipe specimens in pure axial tension. Results are presented for the strength of both materials as a function of temperature and the test environments. It is shown that the axial strength of these pipes is significantly reduced at elevated temperatures, that the degree of this reduction is dependent on the matrix material and is magnified by sea water absorption and that dissolved $\mathrm{CO}_{2}$ and $\mathrm{H}_{2} \mathrm{~S}$ have little effect [8].

Correia, J. R et al present the results of experimental research on the physical, chemical, mechanical and aesthetical changes of glass fiber reinforced polyester profiles after exposure to four different environments: (i) immersion in water at $20^{\circ} \mathrm{C}$, (ii) condensation of water at $60^{\circ} \mathrm{C}$ (iii) accelerated weathering in UV equipment and (iv) accelerated weathering in Xenon-arc equipment. Results include the weight change, tensile and flexural properties, the chromatic change and the chemical resistivity. Considerable chromatic changes were observed, especially due to UV radiation. Regarding structural safety, although some reduction in the mechanical properties was observed, especially in the immersion and condensation chambers, the durability tests proved the generally good behavior of this material under those aggressive conditions [9].

Wang J. and others investigated the durability of glass fiber-reinforced polymer composites under sustained loads and simultaneously exposed to either saltwater or tap water. The tensile properties of the specimens before and after conditioning were evaluated along with their mass up growth under combined effects. The mass change in saltwater was greater than that in tap water. It was observed that the tensile strength and modulus were increasing initially upon immersion, but after prolonged immersion, the tensile properties decreased as the sustained loading increased. However, the tap water immersion had less detrimental effect on tensile properties of glass fiber-reinforced polymer than saltwater [10].

\section{Polyester materials}

The term polyester covers a very large chemical family and there are two major groups:

- thermoplastic polyesters (often called saturated polyester) can be reversibly heated and

- thermoreactive polyesters (called unsaturated polyester) are irreversible formed from low molecular weight precursor of low viscosity which enables good fiber wet-out and filler dispersion [11].

Crosslinking chemical reactions of unsaturated polyesters is caused by the action of heat and pressure, oxidation, radiation and/or other means often in the presence of curing agent and catalyst. Under the influence of mentioned factors thermoreactive materials flow, solidify and, owing to formed three-dimensional structure, become infusible and insoluble [12].

Unsaturated polyesters are usually manufactured by chemical reaction of dihydroxylated alcohols (diols) and dibasic organic acids, either one or both of which contain a double bonded carbon atoms. The properties of the crosslinked unsaturated polyester resins depend on the types of dicarboxylic acids and diols used and their relative proportions. 
Unsaturated polyesters, of general formulae -[O- $\mathrm{R}_{1}-\mathrm{O}-\mathrm{CO}-$ $\mathrm{CH}=\mathrm{CH}-\mathrm{CO}]_{\mathrm{n}^{-}}$, are reaction product of maleic acid anhydride and diols, where $\mathrm{R}_{1}$ denotes alkyl part of alcohol. Part of maleic acid anhydride may be replaced by other dibasic organic acid such are orthophthalic acid (anhydride), isophthalic acid, terephthalic acid or hexahloroendomethylene tetrahydrophthalic acid (HET acid). Dihydroxylated alcohols may be ethylene glycols, 1,2 propylene glycols, neopentyl glycols or etoxylated or propoxylated bisphenols [13].

A general reaction scheme for producing an unsaturated polyesters resin is presented in Fig.1 [11]:

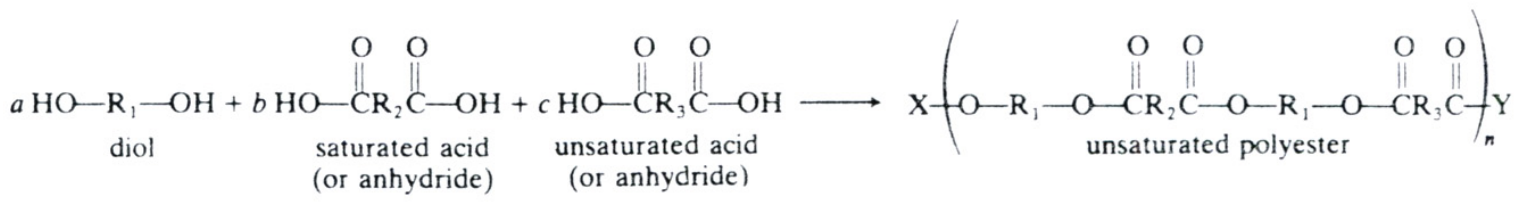

Figure 1. General reaction scheme for producing an unsaturated polyesters resin [11]

For example, general purpose unsaturated polyester resins are made using ethylene glycol as diol, either orthophthalic or isophthalic acid as saturated diacid and fumaric acid-usually generated in situ from maleic anhydride-as unsaturated acid.

The number of terminal groups, $\mathrm{X}$ and $\mathrm{Y}$, depends of mole ratio $\mathrm{a} /(\mathrm{b}+\mathrm{c})$ of dihydroxylated alcohols and dibasic acids used in polymerization. The degree of polymerization, $n$, is small and usually varies between 3 and 15 [11].

An example of producing of bisphenol A based unsaturated polyester resin is presented in Fig.2. Bisphenol A based unsaturated polyester resin is produced using reaction product between bisphenol A and propylene oxide (i.e. propoxylated bisphenol A) and maleic acid anhydride (which converts to unsaturated fumaric acid) [11].

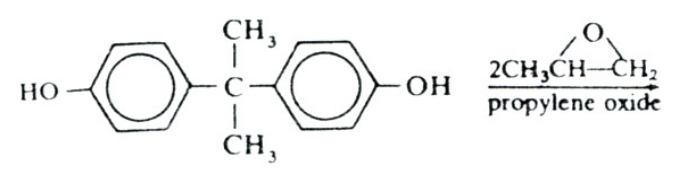

$$
\begin{gathered}
\mathrm{O}_{{ }_{C}} \mathrm{O}_{\mathrm{C}}=\mathrm{O} \\
\mathrm{HC}=\mathrm{C}_{\mathrm{H}}
\end{gathered}
$$

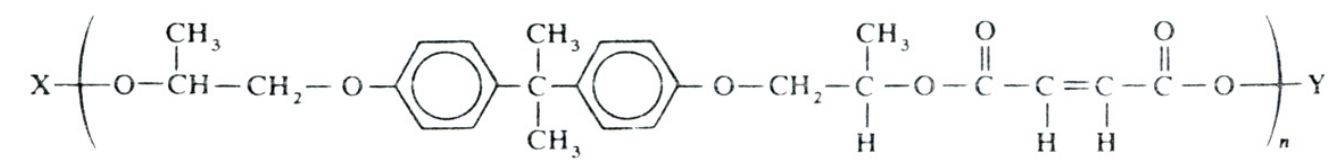

Figure 2. Reaction scheme for producing a bisphenol A based unsaturated polyesters resins [11]

Thermoreactive unsaturated polyesters resins are named according to their properties (general purpose, flexible and semi-rigid, flame resistant, light stable and weather resistant, chemical resistant, flame resistant, high-heat distortion, electrical resistant...) and according to processing procedures (hot strength, i.e. "hot" moulding easily removed from die, low exothermic, extended pot life, air dry, thixotropic...) [12].

Bisphenol A propoxylated-based thermoreactive polyester resins show improved chemical and corrosion resistance over orthophthalic and isophthalic polyester resins. Both properties are generally improved by increasing resin aromatic character, the crosslinking density and the steric hindrance of the ester bond. These factors tend to reduce the absorption of water and other polar molecules. This is important because interaction of water and chemicals at the fiber-resin interface can affect the composite materials properties (fatigue resistance and nature of crack propagation) [13].

Formulae of orthophthalic, isophthalic and bisphenol A polyester resins are presented in Fig.3.

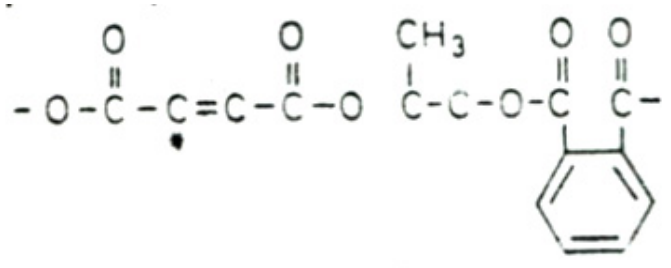

(a)<smiles>COC(=O)C=CC(=O)OC(C)COc1ccc(C(C)(C)c2ccc(OCC(C)C)cc2)cc1</smiles>

(b)

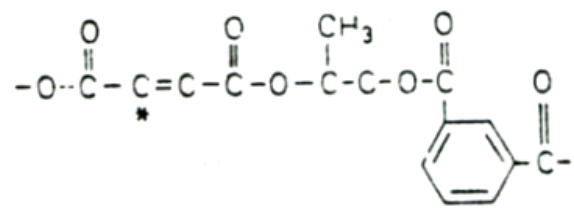

(c)

Figure 3. Formulae of orthophthalic (a), isophthalic (b) and bisphenol A (c) polyester resins

Ester group may be susceptible to hydrolysis especially under the influence of external factors (mainly water, chemicals, etc.). Bisphenol A polyester resin has only two ester groups in structural unit in contrast to orthophthalic and isophthalic polyester resins, which have four ester groups. Two ester groups at bisphenol A polyester resin are in the vicinity of double bond of carbon atoms $\left(\mathrm{C}^{*}\right)$, where a polymerization takes place, which in addition contribute to the stability of this resin class. This statement is valid only for two of four ester groups at orthophthalic and isophthalic polyester resins, and two other ester groups of mentioned resins remain weak places and are exposed to the negative influence of water (mainly). 
The resulting unsaturated polyester moiety is dissolved in polymerizable solvent, usually in styrene (rarely in methyl methacrylate and diallyl phthalate).

The styrene performs the important function of enabling the resin to transforms from a liquid to a solid by 'crosslinking' the molecular chains of the polyester. The molecular chains of the polyester are presented in Fig.4, where 'B' indicates the reactive sites in the molecule.

$$
-\mathbf{A}-\mathbf{B}-\mathbf{A}-\mathbf{B}-\mathbf{A}-\mathbf{B}-\mathbf{A}
$$

Figure 4. Molecular chains of unsaturated non-cured polyester resin

In the presence of a catalyst (which simply activates the process) and accelerator (which enable the reaction to proceed at workshop temperature and/or at a greater rate), the styrene 'S' cross-links the polymer chains at each of the reactive sites of a resin to form a highly complex three-dimensional network as is presented in Fig.5:

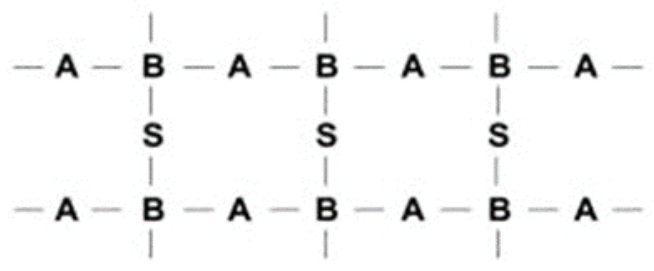

Figure 5. Chemically cross-linked molecular chains of polyester resin

The thermoreactive unsaturated polyesters including orthophthalic, isophthalic, bisphenolic, vinyl esters and blends form the largest single group of fiber reinforced thermoset composite products [12].

\section{Polymeric composite materials}

A polymeric matrix composite (PMC) materials belong to basic engineering materials and consist of polymer impregnating phase in which a reinforcing phase, such as fibers and powders, is embedded.

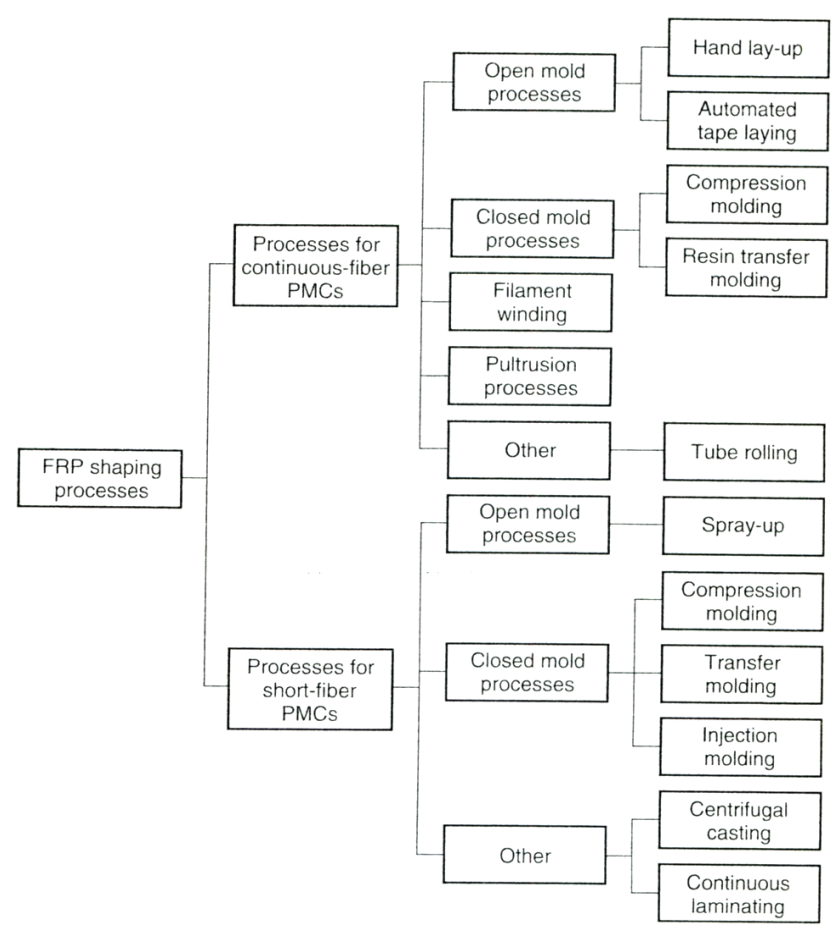

Figure 6. Classification of manufacturing processes for fiber-reinforced polymer composites [14]
The technological and economical importance of manufacturing processes of composites derives from the growing use of this class of materials, especially fiber reinforced polymers (FRP).

Classification of manufacturing processes, by which the polymer matrix composites are shaped into useful components and products, is presented in Fig.6 [14].

Of all thirteen presented single manufacturing processes for fiber reinforced polymer composites, only an increasingly used filament winding technology will be described, shortly.

Filament winding process, in brief, consists of winding of continuous fibers, just impregnated by liquid resin, on rotating mandrel that has a shape as is the internal shape of desired fiber reinforced polymer product. The resin is subsequently cured and the mandrel is removed. In this way, hollow axisymmetric components (usually circular in cross section) are produced, as well as no symmetrical shapes. Filamentwound composite materials have a unique set of specific properties so, very often, they represent an only choice for numerous purposes [15].

\section{Experimental part}

Experimental part comprises the activities concerning neat, non-reinforced bisphenol A polyester resin and composite material obtained by impregnation of glass fiber with bisphenol A polyester system.

\section{Neat resin experimental part}

Casting of bisphenol A polyester system was done in a way that neat resin specimen dimensions $120 \mathrm{~mm} \times 15 \mathrm{~mm} \times 10$ $\mathrm{mm}$ were obtained. Bisphenol A polyester system was consisting of bisphenol A polyester resin mark DUGAPOL BS PIU, hardener mark N (the $50 \%$ solution of methyl ethyl ketone peroxide in toluene) and an accelerator $\mathrm{N}$ (the $6 \%$ solution of cobalt naphtenate in dimethyl phthalate) produced by the DUGA polyester resin manufacturer, Serbia. Curing of casted specimen was done according to resin system manufacturer instructions.

Aqueous solution of calcium hypochlorite, aqueous solution of sodium hydroxide, aqueous solution of sulphuric acid, aqueous solution of citric acid with liquid detergent were used $[16,17,18]$.

Immersion of cured neat resin specimen of mentioned dimensions compromises an influence of following agents:

- aqueous solution of calcium hypochlorite [in further text: $\mathrm{Ca}(\mathrm{OCl})_{2}$ ] concentration $3.5 \mathrm{w} / \mathrm{v} \%$.

- aqueous solution of sodium hydroxide [in further text $\mathrm{NaOH}$ ] concentration $2.5 \mathrm{w} / \mathrm{v} \%$,

- aqueous solution of sulphuric acid [in further text: $\mathrm{H}_{2} \mathrm{SO}_{4}$ ] concentration $2.5 \mathrm{w} / \mathrm{v} \%$,

- aqueous solution of citric acid [in further text: citr.ac.] concentration $2.5 \mathrm{w} / \mathrm{v} \%$ and liquid detergent [hereinafter: liq. det.] concentration $3.5 \mathrm{w} / \mathrm{v} \%$.

Influence of aqueous solution of calcium hypochlorite in laboratory conditions imitates an influence of water purification, i.e. disinfection agent.

Influence of aqueous solution of sodium hydroxide and aqueous solution of sulphuric acid imitate an influence of agents which are used for removing the contaminants from active decontamination substance and regeneration of the same.

Influence of aqueous solution of citric acid and liquid detergent imitate an influence of medium which is used for washing and cleaning the filter for decontamination.

Neat resin specimen were exposed to the influence of every single above mentioned aqueous solution for determined time and to cumulative influence of all reported aqueous solutions, 
also, in a certain period of time.

Determination of mass change of neat resin specimen with elapsed time was done in single influence experiment and in cumulative influence experiment.

Testing of physical and mechanical characteristics of neat resin specimen before and after single influence of every chemical agent and cumulative influence of all chemical agents embrace determination of hardness and impact resistance $[19,20]$.

Analyses of concentration of reported chemical compounds aqueous solutions were done before and after immersion of neat resin specimen.

\section{Polymeric composite material experimental part}

Manufacturing of reinforced tubes was done by filament winding technology of glass roving trade mark R 2117 (made by the ETEX glass fibre manufacturer, Baljevac/Ibar) impregnated with bisphenol A polyester system trade mark DUGAPOL BS PIU (made by the DUGA polyester resin manufacturer, Serbia). Polymeric composite tubes were wound on a cylindrical mandrel about $60 \mathrm{~mm}$ in diameter using the PLASTEX type PLA 500 machine (made by the PLASTEX-MANUHRINE machine manufacturer, France).

Machining of cured glass fiber/bisphenol A polyester system tubes was done in a standard manner and ring specimen $10 \mathrm{~mm}$ wide and cylinder specimen $400 \mathrm{~mm}$ long were produced.

Immersion of glass fiber/bisphenol A polyester system ring and cylinder specimen encompassed exposing of rings and cylinders to the influence of calcium hypochlorite aqueous solution, only.

Determination of a mass change of above reported ring specimen with elapsed time means that mass of reported rings were measured before and after the influence of calcium hypochlorite aqueous solution.

Determination of mechanical characteristic of ring specimen before and after an immersion in aqueous solution of specific chemical compounds involved the testing of tensile breaking force and tensile strength of reported rings [21].

Determination of hydraulic burst pressure of glass fiber/bisphenol A polyester system cylinder specimen before and after an immersion in aqueous solution of calcium hypochlorite consists of testing of a burst pressure in a short period of time. The burst pressure is determined under the influence of internal hydraulic pressure of water and the air was around a cylinder specimen (version water-air) [22].

Analyses of concentration of calcium hypochlorite aqueous solution were done before and after immersion of glass fiber/bisphenol A polyester system ring specimen and cylinder specimen [23].

\section{Results and discussion}

\section{Neat resin investigation results and discussion}

The results of mass change of one neat resin specimen with elapsed time in experiment with single influence of aqueous solution of $\mathrm{Ca}(\mathrm{OCl})_{2}$, aqueous solution of $\mathrm{NaOH}$, aqueous solution of $\mathrm{H}_{2} \mathrm{SO}_{4}$ and aqueous solution of citr.ac. and liq. det. are presented in Table 1 [24].

Considering, purely numerically, data related to single influence of four mentioned aqueous solutions to mass change, presented in Table 2 , it can be seen that $\mathrm{Ca}(\mathrm{OCl})_{2}$ induced the highest and $\mathrm{NaOH}$ the lowest change. But the fact that $\mathrm{Ca}(\mathrm{OCl})_{2}$ induced the mass change of only $0.2096 \%$ for period of even $360 \mathrm{~h}$, pointed out that this change is negligible.
Table 1. Mass change and mass up growth of neat resin specimen during single influence of aqueous solution of specific chemical agents

\begin{tabular}{|c|c|c|c|c|c|c|c|}
\hline \multirow{2}{*}{$\begin{array}{l}\text { Chemical } \\
\text { agenses }\end{array}$} & \multicolumn{7}{|c|}{$\begin{array}{l}\text { Specimen mass }(\mathrm{g}) \\
\text { Mass up growth }(\%)\end{array}$} \\
\hline & $0 \mathrm{~h}$ & $3 \mathrm{~h}$ & $6 \mathrm{~h}$ & $24 \mathrm{~h}$ & $48 \mathrm{~h}$ & $240 \mathrm{~h}$ & $360 \mathrm{~h}$ \\
\hline \multirow{2}{*}{$\mathrm{Ca}(\mathrm{OCl})_{2}$} & \multirow{2}{*}{19.5065} & $\underline{19.5108}$ & 19.5113 & 19.5147 & 19.5191 & $\underline{19.5395}$ & 19.5459 \\
\hline & & 0.0220 & 0.0246 & 0.0420 & 0.0646 & 0.1692 & 0.2020 \\
\hline \multirow{2}{*}{$\mathrm{NaOH}$} & \multirow{2}{*}{18.1657} & 18.1689 & 18.1698 & 18.1719 & 18.1743 & 18.1869 & 18.1930 \\
\hline & & 0.0176 & 0.0226 & 0.0341 & 0.0473 & 0.1176 & 0.1503 \\
\hline \multirow{2}{*}{$\mathrm{H}_{2} \mathrm{SO}_{4}$} & \multirow{2}{*}{19.1994} & 19.2010 & 19.2024 & 19.2066 & 19.2114 & 19.2320 & 19.2357 \\
\hline & & 0.0083 & 0.0156 & 0.0375 & 0.0625 & 0.1698 & 0.1891 \\
\hline \multirow{2}{*}{$\begin{array}{c}\text { citr.ac. }+ \\
\text { liq.det. }\end{array}$} & \multirow{2}{*}{19.6822} & 19.6837 & 19.6838 & 19.6899 & $\underline{19.6947}$ & $\underline{19.7102}$ & $\underline{19.7182}$ \\
\hline & & 0.0076 & 0.0081 & 0.0391 & 0.0635 & 0.1514 & 0.1824 \\
\hline
\end{tabular}

Testing of mass change with elapsed time in experiment with single influence of aqueous solutions were done using seven neat resin specimens. Arithmetic mean value and standard deviations of mass changes of mentioned seven specimens $(\bar{X} \pm \sigma)$, as well as concentrations of used chemicals, are presented in Table 2 [24]. Arithmetic mean value and standard deviations of mass changes of neat resin specimens after cumulative influence of all mentioned specific chemicals $(\bar{X} \pm \sigma$ ) of reported concentrations in overall time duration of 1440 hours [360 hours in water solution of $\mathrm{Ca}(\mathrm{OCl})_{2}, 360$ hours in water solution of $\mathrm{NaOH}, 360$ hours in water solution of $\mathrm{H}_{2} \mathrm{SO}_{4}$ and 360 hours in water solution of citr.ac. and liq. det.] are, also, presented in Table 2 [24].

Table 2. Arithmetic mean value and standard deviations of mass changes of neat resin specimens after single influence and after cumulative influence of specific chemicals

\begin{tabular}{|c|c|}
\hline Chemical agents & Mass change $(\bar{X} \pm \sigma),(\%)$ \\
\hline \hline $\mathrm{Ca}(\mathrm{OCl})_{2}(3.5 \mathrm{w} / \mathrm{v} \%)$ & $0.2096 \pm 0.0167$ \\
\hline $\mathrm{NaOH}(2.5 \mathrm{w} / \mathrm{v} \%)$ & $0.1572 \pm 0.0138$ \\
\hline $\mathrm{H}_{2} \mathrm{SO}_{4}(2.5 \mathrm{w} / \mathrm{v} \%)$ & $0.1874 \pm 0.0034$ \\
\hline $\begin{array}{c}\text { Citr.ac. }(2.5 \mathrm{w} / \mathrm{v} \%)+\text { liq.det. }(3.5 \\
\text { w/v \%) }\end{array}$ & $0.1858 \pm 0.0075$ \\
\hline $\begin{array}{c}\mathrm{Ca}(\mathrm{OCl})_{2}, \mathrm{NaOH}, \mathrm{H}_{2} \mathrm{SO}_{4} \text {, citr.ac. and } \\
\text { liq. det. } \\
(\text { cumulative influence })\end{array}$ & $0.3015 \pm 0.0360$ \\
\hline
\end{tabular}

Based on all data presented in Tables 1 and 2 it can be observed that mentioned specific chemicals, either single and cumulative, have inconsiderable influence on mass change of neat bisphenol A polyester system specimens.

Testing of physical and mechanical properties of neat resin specimen before and after single influence of every chemical agent and cumulative influence of all chemical agents include determination of hardness and impact resistance.

Testing of hardness and impact resistance of neat resin specimens before and after single influences of reported chemicals were done using seven mentioned specimens.

It is considered, generally, that polyester resin based product is well fabricated and well cured if Barcol hardness reading is 30 [11].

Results of investigation of hardness and arithmetic mean value and standard deviations of impact resistance $(\bar{X} \pm \sigma)$ of mentioned seven specimens before and after single influences of reported chemicals are presented in Table 3 [24]. In this table are, also, presented results of hardness testing and arithmetic mean value and standard deviations of impact resistance $(\bar{X} \pm \sigma)$ of neat resin specimens after cumulative influence of all mentioned specific chemicals (concentrations as in Table 2) [24]. 
Table 3. Results of investigation of hardness and arithmetic mean value and standard deviations of impact resistance of neat resin specimens after single influences and after cumulative influence of specific chemicals

\begin{tabular}{|c|c|c|c|}
\hline \multicolumn{2}{|c|}{ Characteristics } & Hardness (Barcol) & $\begin{array}{l}\text { Impact resistance } \\
(\bar{X} \pm \sigma)\left(\mathrm{kJ} / \mathrm{m}^{2}\right)\end{array}$ \\
\hline \multicolumn{2}{|c|}{ Before influence of chemicals } & From 34 to 36 & $5.1 \pm 1.8$ \\
\hline \multirow{4}{*}{$\begin{array}{l}\text { After single } \\
\text { influence of } \\
\text { chemicals }\end{array}$} & $\mathrm{Ca}(\mathrm{OCl})_{2}$ & From 33 to 37 & $4.3 \pm 0.9$ \\
\hline & $\mathrm{NaOH}$ & From 33 to 35 & $5.7 \pm 1.0$ \\
\hline & $\mathrm{H}_{2} \mathrm{SO}_{4}$ & From 33 to 36 & $5.4 \pm 1.1$ \\
\hline & citr.ac + liq.det & From 34 to 36 & $5.5 \pm 1.5$ \\
\hline \multicolumn{2}{|c|}{$\begin{array}{c}\text { After cumulative influence of } \\
\mathrm{Ca}(\mathrm{OCl})_{2}, \mathrm{NaOH}, \\
\mathrm{H}_{2} \mathrm{SO}_{4}, \text { citr.ac. and liq. det. }\end{array}$} & From 34 to 36 & $4.2 \pm 0.6$ \\
\hline
\end{tabular}

Detailed data analysis, presented in Table 3 pointed out that used specific chemicals (either single or cumulative) almost have no influence on hardness and impact resistance of neat bisphenol polyester resin specimens. By analyzing results of investigation in Table 3, at the first view, it seems that there was some change of impact resistance after cumulative influence of all specific chemicals, which is $(4.2 \pm 0.6) \mathrm{kJ} / \mathrm{m}^{2}$, i.e. from $3.6 \mathrm{~kJ} / \mathrm{m}^{2}$ to $4.8 \mathrm{~kJ} / \mathrm{m}^{2}$. Considering that impact resistance before the influence of all specific chemicals is $(5.1 \pm 1.8) \mathrm{kJ} / \mathrm{m}^{2}$, i.e. from $3.7 \mathrm{~kJ} / \mathrm{m}^{2}$ to $6.9 \mathrm{~kJ} / \mathrm{m}^{2}$, it is obvious that value of reported characteristic (tested after influence of all specific chemicals) is inside the interval of starting quality.

Analysis of concentration of reported chemical compounds aqueous solutions were done before and after immersion of neat resin specimen.

Parallel testing pointed out that there are no differences in concentrations changes of aqueous solutions of mentioned specific chemicals, in which neat resin specimens were immersed, and concentrations changes of "blind samples" (without neat resin specimens) of reported solutions of the same chemicals.

All investigations of neat resin specimens were done at ambient temperature.

\section{Reinforced polymeric composite material investigation results and discussion}

Investigation results of polymeric composite material embrace results of investigation of reinforced rings and cylinder specimen.

Based on results of investigation of mass change neat resin specimens with elapsed time (presented in Table 1) and results of investigation of hardness and of impact resistance of neat resin specimens (presented in Table 3 ) in experiments with single influence of aqueous solution of $\mathrm{Ca}(\mathrm{OCl})_{2}$, aqueous solution of $\mathrm{NaOH}$, aqueous solution of $\mathrm{H}_{2} \mathrm{SO}_{4}$ and aqueous solution of citric acid and liquid detergent, it was decided that reinforced rings and cylinder specimen would be exposed to the influence of aqueous solution of $\mathrm{Ca}(\mathrm{OCl})_{2}$, only.

Reinforced rings and cylinder specimen were immersed in aqueous solution of $\mathrm{Ca}(\mathrm{OCl})_{2}$ for 1128 hours (47 days).

Arithmetic mean value and standard deviations $(\bar{X} \pm \sigma)$ mass changes of reinforced rings after the influence of aqueous solution of $\mathrm{Ca}(\mathrm{OCl})_{2}$ (concentration as in Table 2) are presented in Table 4 [24].

Table 4. Arithmetic mean value and standard deviations mass changes of reinforced rings after the influence of aqueous solution of $\mathrm{Ca}(\mathrm{OCl})_{2}$

\begin{tabular}{|c|c|}
\hline $\begin{array}{c}\text { After the influence of aqueous so- } \\
\text { lution of } \mathrm{Ca}(\mathrm{OCl}) 2\end{array}$ & Mass change $(\bar{X} \pm \sigma),(\%)$ \\
\cline { 2 - 2 } & $0.2101 \pm 0.0140$ \\
\hline
\end{tabular}

Investigation of the mechanical characteristics of reinforced rings consists of determining the resistance of ring to internal tensile stress in radial direction (so called tensile breaking ring force) and tensile strength of mentioned rings.

An arithmetic mean values and standard deviations of tensile breaking ring force ( $\bar{X} \pm \sigma$ ) and tensile strength $(\bar{X} \pm$ $\sigma)$ of seven reinforced rings before and seven reinforced rings after the influence of aqueous solution of $\mathrm{Ca}(\mathrm{OCl})_{2}$ (concentration as in Table 2) are presented in Table 5.

Table 5. Arithmetic mean values and standard deviations of tensile breaking ring force and tensile strength of reinforced rings before and after the influence of aqueous solution of $\mathrm{Ca}(\mathrm{OCl})_{2}$

\begin{tabular}{|c|c|c||}
\hline Characteristics & $\begin{array}{c}\text { Before the influence of } \\
\text { aqueous solution of } \\
\mathrm{Ca}(\mathrm{OCl}) 2\end{array}$ & $\begin{array}{c}\text { After the influence of } \\
\text { aqueous solution of } \\
\mathrm{Ca}(\mathrm{OCl}) 2\end{array}$ \\
\hline $\begin{array}{c}\text { Tensile breaking ring force } \\
(\bar{X} \pm \sigma),(\mathrm{N})\end{array}$ & $8501 \pm 537.3$ & $8344 \pm 357.6$ \\
\hline $\begin{array}{c}\text { Tensile strength }(\bar{X} \pm \sigma), \\
(\mathrm{MPa})\end{array}$ & $250.0 \pm 15.8$ & $245.5 \pm 15.8$ \\
\hline
\end{tabular}

Based on results, presented in Tables 4 and 5, it is visible that water solution of $\mathrm{Ca}(\mathrm{OCl})_{2}$, as the most aggressive of all used specific chemicals, causes negligible changes of mass, tensile breaking force and tensile strength of reinforced rings.

Arithmetic mean values and standard deviations $(\bar{X} \pm \sigma)$ of hydraulic burst pressure of three reinforced cylinder specimens before and three reinforced cylinder specimens after the influence of aqueous solution of $\mathrm{Ca}(\mathrm{OCl})_{2}$ (concentration as in Table 2) are presented in Table 6.

Table 6. Arithmetic mean values and standard deviations of hydraulic burst pressure of reinforced cylinder specimens before and after the influence of aqueous solution of $\mathrm{Ca}(\mathrm{OCl})_{2}$

\begin{tabular}{|c|c|c|}
\hline Characteristics & $\begin{array}{c}\text { Before the influence of } \\
\text { aqueous solution of } \\
\mathrm{Ca}(\mathrm{OCl})_{2}\end{array}$ & $\begin{array}{c}\text { After the influence of } \\
\text { aqueous solution of } \\
\mathrm{Ca}(\mathrm{OCl})_{2}\end{array}$ \\
\hline \hline $\begin{array}{c}\text { Hydraulic burst pres- } \\
\text { sure }(\bar{X} \pm \sigma),(\mathrm{MPa})\end{array}$ & $31,0 \pm 1.0$ & $30.2 \pm 1.2$ \\
\hline
\end{tabular}

Data from Table 6 pointed out that water solution of $\mathrm{Ca}(\mathrm{OCl})_{2}$, practically, does not cause the change of hydraulic burst pressure of reinforced cylinder specimens.

Calcium hypochlorite is a chemical agent that spontaneously decomposes.

Concentration changes of aqueous solution of $\mathrm{Ca}(\mathrm{OCl})_{2}$, in which reinforced rings and tube specimens were immersed, and concentration change of "blind samples" of reported solutions of the same chemical (without reinforced rings and cylinder specimens), are presented in Table 7 [24].

Table 7. Concentration changes of aqueous solutions of $\mathrm{Ca}(\mathrm{OCl})_{2}$ with and without reinforced rings and cylinder specimens after 1128 hours

Concentration change of aqueous solutions of $\mathrm{Ca}(\mathrm{OCl}) 2(\mathrm{w} / \mathrm{v} \%)$

With reinforced rings and tube $\quad$ Without reinforced rings and cylinder specimens specimens 75 69

It is important to point out that reinforced rings and cylinder specimens have no influence to aqueous solution of $\mathrm{Ca}(\mathrm{OCl})_{2}$.

All investigations of reinforced rings and reinforced cylinder specimens were done at the ambient temperature.

\section{Conclusions}

Based on the abovementioned, it can be stated:

1. Polymeric composite material, which consists of bisphenol A polyester resin and glass fiber, can be used for manufacturing of filter housing for purification of highly corrosive water solutions. 
2. Circular shape housing of filter for purification of corrosive water can be manufactured by filament winding of glass fiber impregnated with bisphenol A polyester system.

3. Medium for purification of water, medium for regeneration of active substance and medium for washing and cleaning of filter for purification of corrosive water, have no influence neither to no reinforced bisphenol A polyester resin system nor to composite reinforced glass fiber/bisphenol A polyester resin material.

4. No reinforced bisphenol A polyester resin system and composite reinforced glass fiber/bisphenol A polyester resin material have no influence on concentration changes of water solution of calcium hypochlorite.

\section{Literature}

[1] LEIVA-GARCÍA,R., MUÑOZ-PORTERO M.J., GARCÍAANTON,J.: Influence of calcium hypochlorite on the corrosion behaviour of metal components of residential water pipes, International Conference on energy, environment, entrepreneurship, innovation (ICEEEI '11), ISBN: 978-1-61804-001-5, ISSN: 2223-277X, Lanzarote, Canary Islands, Spain, May 27-29, 2011, , pp.76-81.

[2] ASTM International: ASTM G15-08 Standard Terminology Relating to Corrosion and Corrosion Testing, 2008.

[3] AWWARF. Internal Corrosion of water distribution systems. AWWARF-DVGW-TZW cooperative research report.; Denver, CO, 1996, p. 586.

[4] FARMER,T.J., CASTLE,R.L., CLARK,J.H., MACQUARRIE,D.J.: Synthesis of Unsaturated Polyester Resins from Various Bio-Derived Platform Molecules, International Journal of Molecular Sciences, 2015, 16, pp. 14912-14932; doi:10.3390/ijms160714912, ISSN 1422-0067.

[5] Water New Zealand Conference \& Expo 2010, The Use of GRP Pipe in Water and Wastewater Systems, pp 1-9.

[6] HIGH STRENGTH PIPING: Composite/steel pipe designed for extended service in hostile conditions, http://www.offshoremag.com/articles/print/volume-61/issue-3/news/high-strength-pipingcomposite-steel-pipe-designed-for-extended-service-in-hostileconditions.html

[7] AL-HADHRAMI,L., MASLEHUDDIN,M., RIZWAN,M.A.: Chemical Resistance and Mechanical Properties of Glass FiberReinforced Plastic Pipes for Oil, Gas, and Power-Plant Applications, Journal of Composites for Construction, 20(1),June 2015, pp. 04015031-1 to 04015031-8, https://doi.org/10.1061/(ASCE)CC.19435614.0000592 .

[8] HALE,J.M., GIBSON,A.G., SPEAKE,S.D.: Tensile strength testing of GRP pipes at elevated temperatures in aggressive offshore environments, J. Compos. Mater. , Vol 32, Issue 10, 1998, pp.969-986, https://doi.org/10.1177/002199839803201004.

[9] CORREIA,J.R., CABRAL,F,S., BRANCO,F.A., FERREIRA,J.G., EUSÉBIO,M. I., RODRIGUES,M.P.: Durability of glass fibre reinforced polyester (GFRP) pultruded profiles used in civil engineering applications, 3rd Int. Conf. Composites in Construction, Lyon, 11-13 July, 2005, pp.1-9.

[10] WANG,J., GANGA RAO,H., LIANG,R., ZHOU,D., LIU,W., FANG,Z:: Durability of glass fiber-reinforced polymer composites under the combined effects of moisture and sustained loads, Journal of Reinforced Plastics and Composites, Volume 34, issue: 21, November 1, 2015, pp.1739-1754. https://doi.org/10.1177/0731684415596846

[11] KELLY,A.: Concise Encyclopaedia of Composite Materials, Pergamon Press. Oxford. 1989

[12] ROSATO,D.V., ROSATO,D.V.: Reinforced Plastics Handbook, 3rd ed., Elsevier Advanced Technology Ltd., Oxford, 2004, ISBN 18561 74506.

[13] ELIAS,H.G.: Introduction to Plastics, Wiley-VCH GmbH and Co. K Ga A, Weinheim, 2003.

[14] GROOVER,M.P.: Fundamentals of Modern Manufacturing, Materials, Processes and Systems, John Wiley and Sons Inc., Hoboken, 2010, ISBN 978-0470-467008.

[15] RADUlOVIĆ,J.: Filament Wound Composite Plastic Tubes: Relationship Between Winding Structures and Their Hydraulic and Mechanical Properties, Scientific Technical Review, ISSN 1820-0206, 2011, Vol.61, No.3-4, pp.73-77.

[16] ASTM E1229-16, Standard Specification for Calcium Hypochlorite, ASTM International, West Conshohocken, PA, 2016.

[17] SRPS H.B1.032:1992 Sodium hydroxide for industrial use (solid form) - Technical requirements, Institute for Standardization of Serbia, Belgrade, 1992.

[18] SRPS H.B1.011:1981 Sulphuric acid (concentrated) for industrial use Technical requirements, Institute for Standardization of Serbia, Belgrade, 1981.

[19] ASTM D2583-13a, Standard Test Method for Indentation Hardness of Rigid Plastics by Means of a Barcol Impressor, ASTM International, West Conshohocken, PA, 2013, www.astm.org

[20] ISO 179-1, Plastics - Determination of Charpy impact properties - Part 1: Non-instrumented impact test, ISO (the International Organization for Standardization), Case postal 56, CH-Geneva 20, Switzerland, 2010.

[21] ASTM D2290-16, Standard Test Method for Apparent Hoop Tensile Strength of Plastic or Reinforced Plastic Pipe, ASTM International, West Conshohocken, PA, 2016.

[22] RADULOVIĆ,J.: Development and Characterization of Non-Standard Extruded Poly(vinyl chloride) Product, Scientific Technical Review, ISSN 1820-0206, 2016, Vol. 66, No.1, pp.40-48.

[23] ASTM D2022-89(2016), Standard Test Methods of Sampling and Chemical Analysis of Chlorine-Containing Bleaches, ASTM International, West Conshohocken, PA, 2016.

[24] RADUlOVIĆ,J., KARKALIĆ,R.: Polymeric Composite Material Assigned to Filter Housing for Purification of Highly Corrosive Contaminated Solutions, $8^{\text {th }}$ International Scientific Conference on Defensive Technologies OTEH 2018, 11-12 October 2018, Belgrade, SERBIA, Proceedings, ISBN 978-86-81123-88-1, pp. 427-431.

\section{Mokro namotano kućište filtera - ključ za racionalno prečišćavanje jako korozivnih rastvora}


imaju veliku otpornost prema pomenutom sredstvu za prečišćavanje.

Zaključeno je da kućište filtera za prečišćavanje jako korozivnih kontaminiranih rastvora može da se proizvede tehnologijom mokrog namotavanja korišćenjem bisfenolne A poliestarske smole i staklenog vlakna.

Ključne reči: tehnologija mokrog namotavanja, prečišćavanje korozivnih rastvora, kućište filtera, poliestarska bisfenolna $\mathrm{A}$ smola, mehaničke karakteristike, fizičke osobine. 